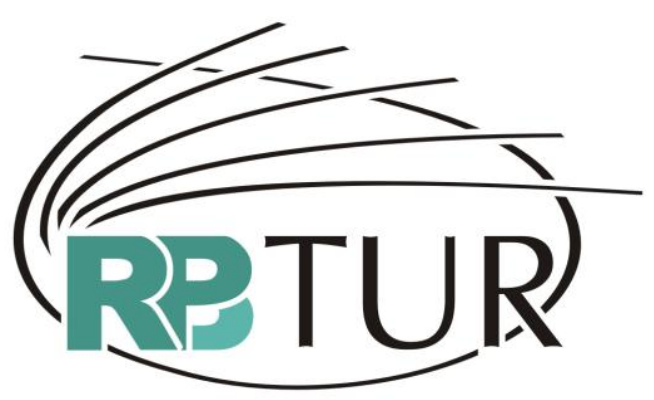

REVISTA BRASILEIRA DE PESQUISA EM TURISMO

\author{
AS FORMAS ELEMENTARES DA HOSPITALIDADE
}

\author{
ELEMENTAL FORMS OF HOSPITALITY
}

\title{
LAS FORMAS ELEMENTALES DE LA HOSPITALIDAD
}

\author{
Maximiliano Emanuel Korstanje ${ }^{1}$
}

\begin{abstract}
Resumo: os estudos modernos têm enfatizado a necessidade de pesquisar a hospitalidade como uma parte importante da atividade turística. No entanto, a abordagem está vinculada à indústria hoteleira, razão pela qual as noções antropológicas da hospitalidade são descuidadas. Assim, o presente artigo tentará contribuir com a compreensão da hospitalidade como fenômeno indo-europeu associado ao princípio econômico, religioso e político das sociedades. Parte-se do pressuposto de que tanto a hospitalidade quanto a hostilidade constituem duas realidades que dialogam na complexa trama social e que merecem ser desconstruídas na linha de análise sinalizada por J. Derrida.
\end{abstract}

Palavras-chave: Hospitalidade. Solidariedade. Hostilidade. Conquista. Amizade.

Abstract: modern studies emphasized on the needs of researching the hospitality as relevant aspects of tourism and hospitality fields. Anyway, these approaches are inextricably intertwined to the industry of tourism and do not take seriously the anthropological and sociological roots of hospitality. In fact, the hotel seems to be a partial sphere of hospitality at all. Under this context, the present paper explores the issue of hospitality enrooted in the political and economic indo-European principle of free-transit which is associated to a much broader origin. Starting from the premise etymologically hostel and hospital share similar origins, we follow the contributions of J Derrida to determine the elements that formed the hospitality up to date.

Keywords: Hospitality. Solidarity. Hostility. Conquest. Friendship.

Resumen: los estudios modernos han enfatizado en la necesidad de investigar la hospitalidad como una parte importante de la actividad turística. No obstante, estos abordajes se hacen vinculados a la industria de la hotelería, hecho por el cual se descuidan las nociones antropológicas de la hospitalidad en sí misma; el hotel al igual

${ }^{1}$ Universidad Argentina John. F. Kennedy. Licenciado en Turismo por la Universidad de Morón y Diplomado Superior en Antropología Social y Política. Ph.D. en Psicología Social, Universidad Argentina John. F. Kennedy. Miembro de la Philosophical Society of England y de la International Society for Philosophers, Reino Unido. Email: maxikorstanje@fibertel.com.ar 
que el hospital son sólo una parte del inmenso mundo de la hospitalidad. Dentro de ese contexto, el presente trabajo teórico intentará ser una contribución al entendimiento de la hospitalidad como fenómeno indo-europeo asociada al principio económico, religioso y político de las sociedades. Partimos del supuesto que tanto hospitalidad como hostilidad conforman dos realidades que dialogan en el complejo entramado social y que ameritan ser deconstruidas en la línea de análisis instaurado por J. Derrida.

Palabras clave: Hospitalidad. Solidaridad. Hostilidad. Conquista. Amistad.

\section{Introducción}

Todas las modas lingüísticas se encuentran atadas a realidades complejas que por un lado evocan pero por el otro dificultan su entendimiento. Precisamente, no hay época más proclive a mencionar a la hospitalidad como la actual y a la vez, a no comprenderla como lo que realmente es, un fenómeno de estructuración política basada en el límite entre la extranjería y el hogar. En ese sentido, el presente artículo intentará ser un análisis crítico que responda a la pregunta ¿Qué se entiende por hospitalidad?. Quien haya estado en contacto con personas de diferente nacionalidad notará que cuando dos extranjeros quienes no hablan la misma lengua coinciden, ambos utilizan la palabra amigo para lograr la entrada en la alteridad. Amigo es la puerta entre el espacio público y privado, entre dos realidades, dos cosmologías, dos culturas que convergen en un mismo plano. $Y$ en ese contexto, amistad y hospitalidad se relacionan. Operacionalmente, la hospitalidad puede ser definida como un proceso ritual que invoca la protección del extranjero bajo la dinámica de circulación material de la propia sociedad, por lo tanto factible de ser comercializada. Los sectores que otorgan hospedaje son aquellos económicamente y políticamente en condiciones de dar dicha protección. Como los dioses protegen a los hombres de las tragedias, los hombres protegen a sus semejantes. En consecuencia, todo proceso de hospitalidad se encuentra asociado a un factor económico, religioso y político.

Inicialmente, parece que existe cierta vinculación con su contralor: la hostilidad. Si nos remitimos a la mitología grecolatina, el mito (fundador) de Prometeo predomina la visión que se tenía sobre la disociación entre trabajo y 
ocio. Recordemos que castigado por haber otorgado al hombre el dominio sobre el fuego, Prometeo (hijo del titán Jápeto) fue condenado -por Júpiter- a que sus entrañas fueran devoradas por un águila durante el día mientras que regeneradas durante la noche eran comidas nuevamente al día siguiente. Luego, Hércules libera a Prometo matando al Ave y dándole al hombre el fuego. Los elementos analíticos que surgen de este relato son claros a grandes rasgos. Dicha visión concuerda con mitos de diversas civilizaciones en cuanto a que existe un proceso cíclico de creación, destrucción para una nueva creación. Análogamente, este proceso obedece a lógica existente entre trabajo y ocio (ELIADE, 2006).

La hospitalidad es el escenario en donde se conjugan las prácticas de la diversión y la vida política. Cuenta la leyenda que tras asesinar al ladrón Caco, Hércules es invitado por el hospitalario rey Faunus, quien buscaba la gloria a expensas de éste. La idea, era simple, y consistía sorprender y dar muerte al legendario héroe mientras era huésped del codiososo rey -con el objetivo simular como aquel que venció al invencible-. Este mito demuestra la naturaleza ambigua que los antiguos le daban a la hospitalidad. Por un lado, ésta ofrecía un aspecto sensual y agradable a la vez que se hacía expresa referencia a la farsa, la mentira y la traición ente otras cosas. En otras palabras, la misma Helena de Troya había raptada por el príncipe Paris bajo hospitalidad y desencadenado un épica cruzada que culminó con la conquista de Troya. Ello infiere que la fascinación de griegos y romanos por la sensualidad (ostentación) y el poder fue una constante a lo largo su historia como civilización. Si bien existen evidencias empíricas que atestiguan sobre la hospitalidad romana (hospitium), las últimas investigaciones demuestran que este concepto no era originario de los pueblos italos, sino que por el contrario fue tomado de los celtas, y quizás aún antes por los germanos. El presente ensayo intentará brindar al lector las bases necesarias para comprender el complejo proceso antropológico de la hospitalidad y como éste se vincula a la territorialización. 


\section{Las Amenazas sobre los Viajeros}

El sociólogo francés Maurice Halbwachs advierte

cierto que en el lugar donde se vive se recibe a los amigos, a los conocidos. Muchos acontecimientos de la vida social se desarrollan en él, encuentran allí su marco natural. Pero el alojamiento es, ante todo, el albergue de la familia. Las expresiones home, foyer, hogar están perfectamente empleadas cuando se dice que los soldados licenciados han sido devueltos a sus hogares. Es el cuadro en el cual se desarrolla la vida doméstica, y en la medida en que se desea asegurar a la familia condiciones de vida confortables y propicias tanto para su intimidad como a su bienestar, se tiende a poseer un alojamiento espacioso, agradable y hasta dentro de ciertos límites, lujoso (HALBAWCHS, 1954, p.152).

En la definición de Halbwachs, la hospitalidad adquiere un sentido positivo sobre el espacio como generador de la vida familiar y social a un nivel primario. De todos modos, la publicidad en un sentido puramente habermasiano puede (también) engendrar conflictos de otra índole. El espacio y el hogar en ocasiones son considerados como fortalezas (reductos) a los cuales se deben proteger. El bárbaro (barbaroi) o extranjero puede ser objeto de exclusión o inclusión. Los exploradores, turistas, viajeros o misioneros se encuentran, en mayor o menor grado, sujeto a similares angustias y contradicciones. Su conocimiento de la tierra que visitan es limitado y se encuentran necesitados de hospitalidad. Se encuentran testimonios en Cicerón sobre el papel que jugaba la adivinación en los viajes romanos. En la Roma del siglo I A.C, movidos por la incertidumbre producida por los desplazamientos hacia zonas lejanas y desconocidas, los viajeros antes de emprender una travesía consultaban a los augures quienes mediante diversos métodos de adivinación inferían las posibilidades de un retorno seguro al hogar. Según los testimonios recogidos por Cicerón, mientras se encontraba de viaje el rey Deyatoro, un día advertido por el vuelo de un águila canceló, su estancia en una posada a la vez que se decidió a continuar su viaje, poco después la 
ISSN: $1982-6125$

misma se derrumbó (Cicerón, I, v. XV, p. 32-33). Misma práctica puede observarse en la actualidad cuando los turistas, viajeros o exploradores se encomiendan a la protección de una figura religiosa. La mitología nórdico escandinava, por su parte, hacía énfasis en la figura de su máximo dios Odín o Wodan, para los anglosajones, quien en forma de animal (preferentemente de Lobo u Oso) recorrían la tierra atravesando diferentes mundos y comarcas. El principio de exploración germano se encuentra sustentado por la misma figura de Odín. El viaje implica una fractura en donde la identidad se encuentra amenazada por la diferencia. Estas amenazas son simbolizadas de diferentes formas brujas, demonios, espíritus, monstruos etc. La Hospitalidad como principio político ayuda a reducir la ansiedad que despierta adentrarse a lo que es "desconocido". En consecuencia, como veremos a continuación los grupos humanos tienden a relacionar la hospitalidad a la extranjería.

Desde una perspectiva moderna, los estudios en materia etnológica en culturas no occidentales evidencian un fenómeno similar bajo otras denominaciones como "susto" para el caso de los Aymará, en donde los viajeros luego de tener contacto ciertos espíritus en territorio extranjero comienzan a enfermar paulatinamente. El hechicero de la tribu debe buscar el equilibrio otorgando a los "demonios" causantes de la dolencia ciertas ofrendas para restituir la aflicción (FERNANDEZ-JUAREZ, 2000, p. 157) (ALBO, 1992, p. 93). Por otro lado, el trabajo de Sir. George Frazer, examina diversos ejemplos de sociedades tribales donde antes de entrar a territorios desconocidos 0 aceptar a viajeros foráneos se realizan diferentes rituales de purificación y restitución sacro-religiosa (FRAZER, 1993, p. 238). Esta evidencia sugiere que las sociedades elaboran su identidad gracias a la creación del "tabú hacia el extranjero".

En esta misma línea, el antropólogo inglés J. Goody explica que entre los Lodagaa en el Norte de Ghana, existe la costumbre de darle agua o en su lugar cerveza al extranjero como señal de hospitalidad. Mediante un intercambio verbal generalmente éste extraño, del cual nada se sabe, es reconducido al estatus "de extraño" y en tal sentido una persona protegida por los dioses 
locales. En ciertos casos, si los viajeros no son bien recibidos basta con comer un puñado de tierra autóctona a la vista de todos para invocar la protección de los dioses. De esta forma, la gente evitará dañar a quien ha sido agraciado con la hospitalidad divina (GOODY, 1995, p. 101). La ingesta de tierra tiene una función simbólica de protección con respecto a la extranjería y las amenazas que generalmente se asocian cuando se está en tierras lejanas.

En este sentido, un trabajo realizado entre los rarámuris en la alta y baja Tarahumara en el estado de Chihuahua, México por el antropólogo español A. Acuña-Delgado muestra como los rituales de Jícuri y bacánowa asociados a la protección y la curación se encuentran en relación con el espacio físico. Las entidades espirituales pueden desarrollar un papel ambiguo, tanto positivo como negativo dependiendo de la relación que se tenga con ellos. El viajero desprevenido puede toparse (sin saberlo) con la ira de estas dos entidades al traspasar sin permiso su hábitat en una laguna o una quebrada al pie de la montaña y encontrar así la enfermedad, la tristeza e incluso la muerte. En efecto, escribe el autor

jícuri y bacánowa ocupan así una posición dual, tanto pueden provocar el bien como el mal, todo depende de cómo sea la relación con ellos, relación que por otro lado, debe estar mediada y dirigida por un especialista que conozca bien sus secretos, que conozca el lenguaje para poder comunicarse con ellos, para saber interpretar que demandan y qué ofrecerle en cada caso, que tengan el don de soñar y conectar con el más allá, con el mundo de las almas de los vivos que viajan mientras duermen, y también de aquellos muertos que aún vagan por el mundo (ACUNADELGADO, 2009, p. 69).

El papel mediador del sipáame (curador) y de la ingesta (mínima) de peyote, el enfermo recupera su salud al restaurar el equilibrio con las entidades involucradas. Sólo el experto reconocido, puede oficiar una ceremonia de esta envergadura puesto de lo contrario, el oficiante asume un serio peligro ya que no puede garantizar ya que genera dependencia y alienación. El viaje como estadio liminar entre la seguridad del hogar y el 
extrañamiento emulan la existencia misma del sujeto y la tensión entre la vida (como lugar seguro) y la muerte. Por ese motivo, los ancestros juegan un rol importante dentro del papel mediador entre el aquí y el más allá. En este punto, el concepto liminar del estado identitario del sujeto se re-elabora discursivamente en un nuevo escenario. En consecuencia, el viaje genera un estado liminar de angustia donde se observa una ambivalencia simbólica entre la incertidumbre ante lo desconocido y la curiosidad por la novedad. La angustia de la extranjería es contrarrestada por medio de los rituales de expiación en los cuales se asienta la hospitalidad.

\section{Discusión en torno al Término Hospitalidad}

Efectivamente, el término hospitalidad deriva del latín hospitium que significa alojamiento. Según Ramos y Loscertales, los celtas (antes que los romanos) manejaban dos significaciones totalmente diferentes para este vocablo. La primera de ellas, se vincula al hecho de recibir a un peregrino y aceptarlo como enviado de los dioses. Se comprendía que el viajero debía ser asistido y hospedado ya que este acto derivaba de un mandato divino; la raíz de este ritual era puramente religiosa. Por el contrario, la segunda significación era netamente jurídica y sólo podía pactarse por convenio entre las partes. En este caso, el hospicio representaba y aseguraba el equilibrio político de los pueblos celtas, y por medio de estos convenios un pacto de no agresión entre ellos (RAMOS Y LOSCERTALES, 1948).

A mediados del siglo $X X$, Alvaro $D$ 'ors analizó la difusión del concepto de hospitium en la península Ibérica. También para este autor, el hospicio ha sido una forma adaptada y adoptada por Hispania para vitalizar las alianzas intertribales entre los diferentes pueblos que coexistían en la región ( $D$ `ORS, 1953). Más recientemente, Ettiene, La Roux y Tranoy parecen haber encontrado evidencia que confirma lo que ya hemos explicado. Los manuscritos hallados (34 para ser exactos) mostraban una idea de 
hospitalidad ya bastante articulada en las poblaciones de origen celta que habitaban en la actual España (ETIENNE, et al. 1987).

Diversos testimonios confirman que los galos ya entablaban en épocas de Julio César pactos de amistad y hospitalidad entre ellos, como el mismo Dictador sugiere en el siguiente texto:

Los menapios estaban cerca del territorio de los eburones, defendidos por lagunas y bosques, y eran los únicos que nunca le habían enviado embajadores para tratar la paz. Sabía que entre ellos y Ambiorix había lazos de hospitalidad. Se había enterado también de que, por medio de los tréveros, había estrechado amistad con los germanos (CESAR, 2004, p. 190).

Asimismo, Grimal nos explica que los celtas, ofrecían y recibían "magníficos" regalos por parte de las tribus vecinas, este hecho marca una especie de peaje hacia los viajeros que tenía su base en una necesidad de libre tránsito y recaudación monetaria (GRIMAL, 2002, p.101).

Si nos imaginamos por un momento, Roma habría sido un centro cosmopolita en donde confluían personajes de diversas partes del mundo entonces conocido. El calendario religioso romano reflejaba una mezcla de jovialidad, divinidad y hospitalidad. Si bien en sus orígenes, eran pocas las festividades religiosas, lo cierto es que en un momento de su historia llegaron a contarse más días festivos que laborales. Las fiestas religiosas ocupaban 45 días del calendario, a las que había que agregar las particulares, barriales y de otra índole. Así, encontramos juegos públicos con arreglo a las fiestas Saturnales, Lupercales, las Equiria y los Seculares (Solá, 2004:33). Al respecto, el testimonio de Séneca es más que elocuente cuando afirma

estamos en el mes de Diciembre, cuando es mayor la fiebre en la ciudad. Las pasiones parecen gozar de absoluta licencia. Por todo se oye el rumor de grandes preparativos, como si entre las saturnales y los días de labor no existiese ninguna diferencia; y de tal manera no hay ninguna, que me parece que tuvo harta razón quien dijo que antes diciembre era un mes y ahora es un año entero" (SENECA, V. I, cart. XVIII, p.48). 
En resumen, la hospitalidad junto al ocio tienen la función de regular las incongruencias del devenir social articulando y replicando sobre las diferentes generaciones los valores culturales que fundan a la sociedad.

\section{La Hospitalidad de los Antiguos}

A nuestro entender, uno de los textos, que mejor trabajado tiene el tema del hospitium latino es el de la profesora Paloma Balbín Chamorro, titulado Ius hospitii y ius civitatis. El autor comienza el artículo haciendo expresa diferencia a la lógica del hospicio en contraposición al patronato, aunque luego profundiza -en concordancia con Humbert (1978)- los orígenes latinos del hospitium. Según Humbert, el hospitium tenía un carácter público (entre comunidades) el cual permitía ciertos derechos al viajante que se asemejaban a una "ciudadanía temporaria"; y el hospitium privado el cual se celebraba sólo entre grupos familiares o sujetos (HUMBERT, 1978). Balbín Chamorro no concuerda con la tesis "de la hostilidad natural", propuesta en su momento por Mommsen, la cual sostenía que cualquier extranjero que llegaba a la ciudad se veía despojado de todos sus derechos de no ser por el hospitium de algún ciudadano. Según esta postura, en definitiva el hospitium es una consecuencia de la hostilidad natural entre los pueblos. Sin embargo, "la tesis de la hostilidad natural no se sostiene; al contrario, las fuentes muestran una relativa facilidad de circulación y de absorción en el interior de la estructura ciudadana de los individuos y grupos foráneos". Algunos textos nos sugieren la idea de que el hospitium ya estaba presente en Halicarnaso y Tito Livio mucho tiempo antes de la constitución del Imperio Romano. (BALBIN-CHAMORRO, 2006, p. 210)

Etimológicamente, el término en cuestión se compone de la fórmula Hostis y Pet. Si bien, hostis parece tener relación directa con "el enemigo", en efecto el hospitium se aplicaba en contextos amistosos, por llamarlos de alguna forma. Esto mismo, es entendido por Chamorro, quien prefiere sostener que existe una línea común en las lenguas indo-europeas con respecto a 
hostis, en un sentido de equilibrio y no de hostilidad. Por algún motivo que el autor no precisa y en algún momento histórico que no describe, hostis (hostia) comienza a tomar un significado de compensación. Asimismo, Chamorro sugiere

hay que tener en cuenta que las nociones de enemigo, extranjero y huésped, que para nosotros designan tres realidades bien diferenciadas, presentan no sólo en latín sino en todas las lenguas indoeuropeas antiguas, estrechas conexiones: al hombre libre nacido en grupo, se opone el extranjero que es a priori un enemigo, aunque susceptible de convertirse en huésped si se establecen con él relaciones de hospitalidad, o en esclavo si se le captura en la guerra (ibid, p. 217).

Por otro lado, la forma Pet hace referencia a "amo", por lo cual el autor asume que "hospes" significa "amo del huésped". La necesidad de trasladarse habría de suponer una cesión temporaria de algunos derechos sin coaccionar u obligar a adoptar alguna ciudadanía en detrimento de la propia. Esto supone, que el término hospes implicaba dos cosas: por un lado, la garantía de libre circulación y por otro, la obligación de prestar auxilio en caso de necesidad. Seguramente, la reglamentación del hospitium latino (antes del Imperio), debió de surgir con la celebración de las fiestas religiosas, las cuales eran visitadas por pueblos vecinos. Prueba inversa de ello, son los testimonios de Livio sobre el rapto de mujeres sabinas. De todos modos,

En nuestra opinión, la conexión entre hospitium y libre asistencia a fiestas religiosas, no estuvo previamente respaldada por pactos previos, sino que a menudo fue el carácter sagrado de estas festividades lo que aseguró un comportamiento grato por las dos partes (ibid, p. 226).

Si bien los autores e historiadores no han podido ponerse de acuerdo en cuando los romanos adoptaron "el hopes" como forma institucional propia, éste tenía una función que por lo menos queda clara a grandes rasgos: el hospitium facilitaba el traslado de personas y ganadería de un territorio hacia otro 
garantizando ciertas libertades y obligaciones por parte del viajero. A su vez, estos pactos requerían de cierta reciprocidad y cobertura legal.

Podemos señalar que incluso la institución del hospitium, coexistía en Hispania y en otras regiones europeas con otras de igual jerarquía. Si bien es difícil poder precisar, bajo que contexto operaba una y otra o por lo menos bajo que rango jurisdiccional, salvo que como advierte Blázquez

el fundamento de algunas instituciones indígenas bajo Roma queda claro en la Tessera hospitalis del año 14, hallada en Herrera de Pisuerga. Al igual que la encontrada en Austurica Augusta, es doble. En el primer texto, la ciudad de los maggavienses otorga a Amparamos la ciudadanía y concede a sus familiares los derechos de que gozaban los maggavienses. En el segundo, Amparamos hace un pacto de hospitalidad con los maggavienses, en virtud del cual, Amparamos, los suyos y los descendientes, recibieron a loas maggavienses en hospicio, fe y clientela, otorgándole los mismos derechos que disfrutan él y los suyos. Las civitas maggaviensium recibió, a su vez, a un particular y éste acogió a sus componentes en hospicio, fe y clientela. Se da un hospitium, un patronatus y una adlectio in civitatem (BLAZQUEZ, 1989, p. 130).

Cada contexto histórico ha condicionado la aplicación del hospitium; así es posible que el Imperio haya proscrito para ciertas provincias en los que un acuerdo militar inter-tribal hubiera sido contraproducente para el estatus jurídico del imperio romano y sus intereses económicos. El Imperio romano extraía de sus colonias las materias primas necesarias para sustentar su aparato político y militar exportando elaborados estilos de consumo. Esta dinámica se sostenía gracias al principio de patronato ciudadano en donde un garante romano disponía de la fuerza suficiente para garantizar la "paz" en la región. El Patronato tenía como función disminuir la presencia del hospitium en las regiones conquistadas.

Por su parte, Balbín-Chamorro apunta a que

Roma no permitiría que los indígenas establecieran entre sí acuerdos de carácter militar, pero en cambio no tendría ningún inconveniente en autorizar relaciones de buena voluntad que 
facilitasen la convivencia entre comunidades - promocionadas 0 no - o que proporcionasen a los extranjeros medios para proteger sus intereses y disfrutar de ciertas comodidades durante su estancia en el territorio (BALBIN-CHAMORRO, 2006, p. 231).

Aunque ésta parezca una idea que debe ser probada y trabajada con mayor profundidad, exige un esfuerzo intelectual que nos lleva a suponer que tanto hospitium como patronatus convivían como formas institucionales que se aplicaban según las necesidades políticas de Roma. La explicación de Chamorro se perfila, consecuentemente, como novedosa y esclarecedora debido a que permite explicar la coexistencia de ambas instituciones; ya no desde un punto de vista cultural sino socio-político.

El mundo cultural romano e indígena en Hispania era tan rico y variado que nos obliga a proponer ciertos puntos intermedios en nuestras afirmaciones. No obstante, acordamos con el profesor Blázquez (ya varias veces citado como un exponente reconocido del tema) que la explotación económica y la asimilación cultural parecen tener cierta relación si reobserva el hecho que las minas en las cuales se trajeron colonos italos (para reforzar la mano de obra) existe un grado de cultura romana mayor en comparación con las minas en donde se utilizó a la población autóctona celta o vasco no indoeuropea. En ocasiones, en que la agricultura era desdeñada como forma principal de ingreso económico por la explotación de la minería, el progreso económico de la población se mantenía bajo. Por el contrario, cuando se combinaban ambas actividades y se daba participación a los indígenas, el progreso era mayor y consecuentemente también la asimilación cultural (ÁLVAREZ, 1963).

Por el contrario, en la modernidad el término hospitalidad parece algo distante al usado en la antigüedad clásica, aun cuando su esencia política continúa. Por un lado, invoca protección al diferente mientras por el otro despierta los más recónditos sentimientos xenófobos hacia el extranjero. En otras ocasiones, la negación o el desconocimiento de la hospitalidad se transforma en la excusa perfecta para la sub-humanización y por ende para 
dar rienda suelta al sentimiento de dominación. Como ya hemos inferido en este trabajo, hospitalidad y hostilidad parecen compartir un mismo significado y raíz etimológica, y ello no es un tema menor.

\section{La Hospitalidad como Mecanismo de Contradon}

En parte no es extraño que hotel y hospital tengan un origen etimológico común: hospitium, término por el cual las tribus indo-europeas celebraban convenios de reciprocidad en épocas de paz, dándole paso a los viajeros y de guerra generando obligaciones de ayuda recíproca en los respectivos campos de batalla. En este sentido, mientras el hospital abre sus puertas (en la mayoría de los casos cuando la medicina es pública) a todos sin restricción aplicando una hospitalidad incondicional, el hotel hace lo propio exclusivamente bajo la dinámica de la hospitalidad restringida, donde el servicio sólo se convierte en una contrapropuesta. Es la ciudadanía aquella destinada a preservar los "espacios de publicidad" frente al inminente avance del capital y a la privatización de la medicina pública. Es precisamente allí, en las sociedades en donde ésta no es posible sino por medio de la imposición de la ley, la hospitalidad restringida invade la esfera de la absoluta poniendo restricciones y agravando la desigualdad entre los hombres. La hospitalidad articula la lógica entre Persona, Estado y Acción. Dicho vínculo nos permite comprender las ambigüedades, incongruencias y desigualdades imperantes en nuestro mundo moderno e inferir las maneras en que el turismo como actividad industrial capitalista corresponde a recrear, construir y reproducir.

En este contexto, el antropólogo Marc Gygax (2007) de la Universidad de Princeton ha rastreado el principio explicativo de la teoría de la hospitalidad en el mundo griego asumiendo su base en el libre juego de los dones mausianos. En efecto, recordemos que Marcel Mauss hace tiempo había propuesto una teoría universal de los dones como aquellos regalos que dos partes se están obligados a realizarse (MAUSS, 1979). 
KORSTANJE, Maximiliano Emanuel. Las formas elementales de la hospitalidad. Revista Brasileira de Pesquisa em Turismo. v.4, n.2, p.86111, ago. 2010.

ISSN: $1982-6125$

Los dones que no se devuelven siguen transformando en inferior a quien los aceptó, sobre todo cuando se recibieron sin ánimo de devolverlos... en esta vida, aparte que es nuestra vida social, no podemos quedar al margen como todavía se dice entre nosotros. Hay que devolver más de lo que se recibió. La vuelta es siempre mayor y más cara" (MAUSS, 1979, p. 247).

A través de la teoría del nexum (romano) y el wadium (germano) Mauss estaba convencido de haber encontrado formas residuales arcaicas (en la cultura europea) que confirman su teoría sobre el don y el origen del derecho (sobre todo del contrato como hoy lo conocemos). Aunque esto pueda ser parcialmente cierto, es necesario detenerse por un momento en este punto y analizarlo bajo una postura de reflexión crítica. Si bien, el autor parece fundamentar convincentemente que el don (en sus diversas formas kula, pokala, potlatch, nexum y wadium entre tanto otros) es un elemento teórico presente en la mayoría de las culturas, parece muy poco interesado en recopilar aquel material que precisamente refuta su idea de darle a la tesis de "las prestaciones" un carácter universal. En resumen, el hombre tiene la necesidad de dar, para recibir para luego volver a dar. De esta forma se funda la reciprocidad entre los actores sociales y se mantiene unida la comunidad. La figura de la solidaridad dio así un instrumento de análisis para muchos antropólogos en épocas posteriores (LEVI-STRAUSS, 2003) (SAHLINS, 1972) (WEINER, 1992). En el mundo griego, nos explica Gygax la hospitalidad estaba fundada en la solidaridad de los dones. El hecho de recibir un bien o un favor, no obstante, generaba un efecto ambiguo en el receptor. Por un lado, uno positivo por el cual quien recibía el regalo se sentía agradecido, en solidaridad con aquel que iniciaba el círculo; sin embargo por otro lado las consecuencias se tornaban negativas por cuanto el receptor se veía en obligación o deuda con quien ofrecía el regalo. De esta forma, el receptor pronto se encontraba obligado a devolver el favor y cerrar su deuda. Esta explicación apunta a comprender como los dones estructuran la solidaridad entre las partes intervinientes y en donde -en última instancia- se inscribe la hospitalidad (GYGAX, 2007: 116). 
En este sentido cabe aclarar que el concepto de hospitalidad europeo fijó las bases de la expropiación territorial en la América de los siglos XVI y XVII. Más precisamente, como demuestra el excelente trabajo histórico de Anthony Pagden que no todas las tribus americanas conocían y manejaban el concepto de reciprocidad, hecho que finalmente llevo a la legitimación de la conquista española. Partiendo de la base que la hospitalidad pertenecía al derecho natural que une a los hombres en su civilidad, los eruditos españoles sostenían que aquellos quienes no pudieran respetar el principio de libre "tránsito y hospedaje" no podrían ser considerados humanos; esta elaboración facilitó la conquista de América pues muchas tribus aborígenes desconocían el principio de hospitalidad europeo y se negaban a que los viajeros españoles atravesaran sus tierras. Despojados simbólicamente los indígenas americanos de su humanidad por los eruditos españoles pronto la expropiación territorial se convertiría una cuestión de ejecución. Ya no existía escollo moral para la conquista de América (PAGDEN, 1997).

\section{La Hospitalidad Condicionada}

La hospitalidad surge de la lengua por la cual se le pide al estado un permiso de entrada que es finito en tiempo y espacio. Un viajero que se rehúsa a hablar "nuestra lengua" es despojado del beneficio de hospitalidad. Para Derrida, la hospitalidad es posible solamente bajo un derecho amparado bajo las figuras de patrimonio y nombre (apellido). En este ritual convergen el límite y la prohibición. En otras palabras, en el anonimato nadie puede recibir hospitalidad porque no tiene lugar de nacimiento, ni historia, ni patrimonio, ni referencia alguna. A un inmigrante es recibido en una tierra bajo el principio de hospitalidad condicional, se le pregunta ¿Quién eres y de donde es que vienes?

En muy raras ocasiones el Estado permite la entrada libre de extranjeros sin una verificación previa. Según Derrida, la hospitalidad condicional es el primer hecho de violencia (coacción) por el cual el Estado se fundamenta como tal frente al xenos, frente al extranjero. Por otro lado, la hospitalidad absoluta 
exige que abra mis puertas ya no sólo a la diferencia que es finita, sino a otros y a un otro absoluto el cual no se debe a ningún tipo de reciprocidad. La verdadera hospitalidad no exige nada a cambio. Por otro lado, entre el huésped y el parásito existe una diferencia abismal. El huésped está condicionado por la ley y el derecho que le dan su sustentabilidad en el patrimonio y la identidad mientras el parásito es "perseguido" e "indeseado" por su estatus.

El derecho de asilo, de esta manera, se da a quienes se introducen en el "hogar" con una historia previa y un origen; en eso se distinguen los invitados de los huéspedes ilegítimos. Pero incluso en la hospitalidad el viajero sigue siendo un extranjero, y aun cuando la recepción sea calida se debe al principio de autoridad de quien le da protección, a sus leyes, y a su lengua. El poder de policía, en principio destinado a perseguir y encarcelar a los huéspedes cuya hospitalidad es ilimitada (fuera de todo derecho) como son los inmigrantes ilegales, en los extranjeros con hospitalidad condicionada encuentra un receptáculo para ciertas demandas que les son funcionales a su rol. En otros términos, mientras un viajero está protegido bajo el principio de hospitalidad, el soberano pone todos sus esfuerzos para que éste no sea dañado, pero siempre y cuando se mantenga como un extranjero en tránsito; si por algún motivo nuestro viajero decide arraigarse, otras fuerzas y mecanismos entrarán en juego. Es cierto que los Estados intolerantes con respecto al xenos (extranjero) focalizan en la diferencia del lenguaje y anulan el principio básico de hospitalidad (visto generalmente en los movimientos nativistas), empero el viajero lleva consigo su lengua materna como marca de nacimiento (aun si se encuentra condenado a morir en tierra de extranjeros como bien examina Derrida en Edipo). Es importante también mencionar que si la lengua, es tomada en un sentido más estricto, la nacionalidad opera directamente por sobre la división del trabajo. En otros términos, un obrero francés tiene más en común con un empresario francés que un obrero palestino: ambos hablan el mismo (o parecido) francés. Por el contrario, si la lengua es comprendida desde un punto más amplio, un burgués intelectual palestino tiene más en 
común con el mismo Derrida que un obrero francés. Los criterios de mismidad y alteridad son tan rígidos o flexibles como la sociedad lo disponga.

Derrida esboza aquí, el principio marxiano de la solidaridad de clase relacionándolo con la hospitalidad y la lengua materna. Esta relación puramente conceptual es importante a la hora de comprender el problema dos motivos principales; el cuerpo de lo nacional se impone en la hospitalidad como en el lenguaje restringido. La extranjería juega un papel impuesto por el Estado limitando la hospitalidad. Como ya años atrás habían propuesto los pensadores marxianos, la "solidaridad de clase" quebranta no sólo la lógica del capital burgués y la ideología (falsa consciencia) sino el principio de hospitalidad en sí. Implícitamente, podríamos afirmar que la hospitalidad se basa en la ley específica de diferencia y similitud propia de los procesos de etno-génesis. La Ley - en general - choca con la ley particular, como el inmigrante choca con el ciudadano y el "huésped con el parásito".

En uno de los más interesantes trabajos filosóficos de revisión sobre la hospitalidad en Derrida, Mark Westmoreland (2008) se pregunta cual es la relación entre la hospitalidad y la interrupción; ¿Por qué el autor invita a comprender o interpretar la misma desde la interrupción? En efecto, la hospitalidad (absoluta) existirá siempre cuando haya subordinación; Occidente por su parte no conoce otra hospitalidad que aquella otorgada condicionalmente (estricta). La hospitalidad - como la ética - no existe sin una cultura que les de alojamiento y a la vez sentido de ser pero la hospitalidad occidental condicionada exige retribución, reclama la ley imponiendo premios y restricciones a quienes la siguen o la desobedecen (WESTMORLAND, 2008). El principio de soberanía burgués, en el sentido de M. Foucault, es parte de la hospitalidad (FOUCAULT, 2000).

Inicialmente como infiere Westmoreland, la hospitalidad fue un pacto religioso y político entre las tribus indo-europeas. Como se ha explicado, ospes (termino arcaico de hospitalidad) deriva en principio de la ley de los hombres (WESTMORLAND, 2008). No obstante, con el transcurrir de los años y lo siglos, éste complejo de proceso de reciprocidad mítico-religioso se transformó en un 
mecanismo para crear hegemonía y fundamentó las bases de la conquista de América; los imperios de la ley no sólo se imponen por medio de la infravalorización del prójimo, sino que utilizaron, utilizan y utilizarán los pretextos de la no hospitalidad para sus incursiones bélicas y guerras preventivas (RAMOS Y LOSCERTALES, 1948) (PAGDEN, 1997). En este punto, hospitalidad y hostilidad se conforman como dos mecanismos que generan alteridad pero de diferente forma. No obstante, ambos dialogan y en la proximidad geográfica - como entre los hermanos - es fácil observar como se pasa de un estado a otro. Ambos principios fundamentan la vida social y política de un grupo humano.

\section{De la Hospitalidad a la Hostilidad}

Para M. Sahlins existen tres tipos de reciprocidad: equilibrada, generalizada, y negativa. En el primer caso, un sujeto se obliga a brindar un bien o servicio que es retribuido por el receptor. Por el contrario, la reciprocidad generalizada se distingue por la falta de obligación en alguna de las dos partes, por regla genera, en aquella que ostenta mayor poder y prestigio. Finalmente, la reciprocidad negativa es aquella por la cual una persona a pesar de haber recibido un don, niega su devolución afectando gravemente el lazo entre ambas. Un ejemplo claro de reciprocidad negativa es la delincuencia (Sahlins, 1972: 195). De esta misma manera, la hospitalidad pone en juego mecanismos de solidaridad entre las partes intervinientes. La visa como permiso temporal puede ser negado u otorgado siguiendo estos mismos parámetros. Si los estados celebran un convenio de visado reciproco se estaría frente a una hospitalidad equilibrada; si un estado otorga visado mientras el otro lo niega, el hecho sería concebido como un caso de hospitalidad negativa o generalizada. Los Estados Unidos de América, el cual a pesar de gozar del beneficio de la no presentación de visa para la visita de sus ciudadanos a Argentina, pero que no corresponde con igual medida para los argentinos que quieren visitar ese país es un fiel ejemplo de lo expuesto. No 
obstante, para una mayor comprensión es necesario comprender los elementos que a nuestro juicio son primarios en la construcción de hospitium, ellos son: a) poder, b) extranjería, c)protección divina ante las tragedias, d) condición de retorno del huésped, e) patrimonio y nombre del huésped y f) ambigüedad.

Todo viajero se encuentra en un dilema identitario, si bien por un lado sigue siendo el mismo, su imagen se altera notablemente en un nuevo ambiente, con nuevos actores, nuevas reglas, etc.. La hospitalidad encierra un elemento de contingencia, o mejor dicho de ambivalencia en donde el viajero puede ser dañado en tanto que ser-desconocido para el resto. En ese proceso tanto hospitalidad como hostilidad dialogan. Mas el viajero que es recibido en concepto de huésped se encuentra subordinado a los deseos de quien otorga la hospitalidad - lo que es el amo. La protección de los viajeros es un mandato divino por cuanto los mismos anfitriones pueden convertirse, llegado el caso, ellos mismos en viajeros o desterrados. Los que mantienen el poder necesitan de la hospitalidad ya sea por necesidad de protección o de ataque. C. Geertz en su excelente libro Negara describe con lujo de detalles como las reglas impuestas por una sociedad, en apariencia para ser cumplidas, en el fondo invitan a ser quebrantadas con el único fin de legitimar una intervención militar por causa de ese incumplimiento (Geertz, 2000). Bajo el pretexto de hospitalidad se esconde el fantasma de la hostilidad, y es precisamente eso lo que habían denunciado los antiguos.

Al respecto, el filósofo alemán, Bernhard Waldenfels advierte

el espacio que habitamos no es puro hogar propio. Es el lugar donde recibimos a los extraños, aunque sean admitidos, rechazados o distanciados. Al mismo tiempo es el lugar de la invasión violenta que transforma a los habitantes en extranjeros en su propia casa, en tanto lo propio se vuelve extraño, y le quita el suelo a la hospitalidad. Incluso la hospitalidad se puede volver enemistad. Una amenaza tal conduce a medidas defensivas que transforman el lugar propio en una fortaleza (WALDENFELS, 2005: 178).

\section{EI Hogar y la Hospitalidad}


El hogar, al igual que la casa, señala la voluntad de crear un grupo unido por relaciones sociales estables, el cual es capaz de reproducirse simbólicamente. Asimismo, el hogar es parte de la misma unidad familiar y garantiza su supervivencia biológica. Desde el prisma antropológico, la disposición de la casa (hogar) es característico de los grupos agrarios (sedentarios) que poseen un vínculo particular con el suelo, el tiempo y la economía. (BORDIEU, 2005:37) (BARHDT, 1970: 105).

F. Jiménez-Guzmán explica que en los orígenes de la humanidad la vida social estaba regida por el principio del nomadismo. En ella, el hombre no se había apropiado del espacio sino que lo hace a medida que puede perfeccionar herramientas de casa y cultivo. Durante este lapso de tiempo, los viajes tenían una función muy específica la búsqueda del alimento. En efecto, como la actividad principal, era la caza, no era conveniente establecer un territorio fijo. Generalmente, en estos casos, las tribus perseguían los rumbos de sus presas. Pero esto no fue eterno, y sobrevino una segunda etapa en la vida de los pueblos conocida como el asentamiento. En este proceso, comienza a suscitarse la necesidad de la división del trabajo y la especialización (asentamiento para el trabajo). La actividad principal de este grupo era la agricultura, por la cual se establecía una organización social basada en el clan y el sistema de trueque. Esta forma de organización comienza a producir un excedente. Este período comienza a entrar en crisis cuando los hombres se dan cuenta que existe la posibilidad de enriquecerse y tomar parte o todo ese excedente (Jiménez Guzmán, 1986:39). Las observaciones del autor intentan en forma evolutiva inferir en una idea que es por lo menos interesante. Si bien esta tesis puede despertar justificadas críticas, es importante resaltar que los hombres han establecido espacios fijos a los cuales llamar hogares y que a medida en que fueron perfeccionándose sus técnicas económicas comenzaron a surgir los excedentes de la producción.

Los linajes, clanes y segmentos de las tribus están compuestos por el parentesco y por la descendencia. El primero cumple una función de unión 
económico-social de un grupo con respecto a otro, mientras que el segundo denota herencia y continuidad. La posesión del suelo ha sido el requisito indispensable para el surgimiento de los segmentos y los linajes y con ellos el conflicto inter-tribal (COHEN, 1985) (ELIAS, 1998) (BALANDIER, 2004). En Balí del siglo XIX existía una serie de tratados (formales o no) tendientes al intercambio de mercancías y personas. Estos tratados tenían una función clara y definida, la integración social. Estos convenios cubrían diversas arenas que iban desde la repatriación de individuos hasta la hospitalidad para aquellos viajeros que se movían de una región a otra. Estas formas de interacción se fundamentaban en sentimientos de cortesía (GEERTZ, 2000, p. 65).

En efecto, como (acertadamente) sostiene el antropólogo inglés, "los tratados parecen haber sido diseñados más para codificar los pretextos con los cuales se podían romper las alianzas que para establecer las bases sobre las que éstas últimas se podían construir" (GEERTZ, 2000, p. 68). Paradójicamente, las alianzas en ciertos contextos operan en forma inversa, generando ansiedad y momentos de competitividad extrema que atentan contra el espíritu de unidad y paz por las cuales se suponen fueron construidas. El concepto de excusa se conforma por medio de pautas (convenidas superficialmente) y que ambas facciones saben que resultarán difíciles de respetar en algún momento del vínculo. Celebrado el contrato (convenido), bajo el manto de la cooperación, el acercamiento y la comprensión inter-grupal, subyace el conflicto, la ambición y el deseo de posesión.

En semejante contexto de perfidia institucionalizada, los tratados, como cualquier otras expresión de alianzas transversales, funcionaban de forma negativa, casi perversa. Más que crear unidad política, proporcionaban un rico diccionario de razones -un delicado insulto, la negligencia de una observancia ritual, un presente inadecuado o una vaca confiscada- por las cuales se podía entender y justificar la ausencia casi completa de la unidad (GEERTZ, 200, p. 69). 
Es posible, en el sentido de Mauss y Malinowski, comprender que el acto de brindar "al otro" la propia morada, implica una retribución similar o mayor en forma de contraprestación (MAUSS, 1972) (MALINOWSKI, 1986). Claro que por un lado no todos comprendían a la hospitalidad como un signo de camaradería y ciertamente tampoco tenían motivos prácticos para poder hacerlo (tema que intentaremos abordar con la mayor objetividad y rigurosidad posible). Por el otro, las convenciones pre-establecidas pueden encerrar causas más allá de su apariencia artificial, que conllevan a justificar ideológicamente - desplegando mecanismos específicos como el etnocentrismo o los prejuicios sociales - ciertas prácticas orientadas a la dominación.

El sentido de conquista implica una sumisión voluntaria por parte de una de las facciones en pugna. No alcanza con ser derrotado, debe existir un común acuerdo de aceptación de la autoridad del vencedor por parte del vencido; el huésped originalmente era un término castrense para denominar al grupo de hombres que formaban parte del botín de guerra. Los antiguos romanos explica Hobbes, llamaban a la conquista de otra forma: pacificación. En otras palabras, cuando los vencidos habían declarado "imperata facere" que equivaldría a lo que el pueblo romano dispusiera, entonces había conquista. Por ese motivo, el hecho de asignarle a la hospitalidad un atributo universal puede ser ampliamente debatido y cuestionado. La derrota y la voluntad de seguir viviendo bajo la dominación del vencedor dieron origen a la esclavitud (Hobbes, 2004: 483). En la siguiente sección veremos que indicadores fiables pueden extraerse de todo lo expuesto para estudiar la hospitalidad desde una perspectiva holística.

\section{Indicadores modernos de hospitalidad}

En la actualidad, la hospitalidad se ha transformado en un mecanismo reductor de la ansiedad y la angustia que despierta en los viajeros la entrada en territorio que les es ajeno. Sin embargo, esta hospitalidad nada en parte parece tener que ver con aquella utilizada en tiempos antiguos. En las 
siguientes líneas discutiremos cuales son los indicadores más representativos de la hospitalidad en las culturas modernas.

1) La visa, puede entenderse como el la protección temporaria que otorga un Estado a una persona extraña. La palabra visa deriva del latin videre, participio de visum, ver. Específicamente, esa es la función de la visa, darle al Estado que la otorga una certeza de las características del viajero el cual peticiona por una hospitalidad temporal.

2) El otro indicador clave es el pasaje aéreo o terrestre de retorno el cual hace referencia expresa al cumplimiento de la petición de visa. Partiendo de la base que la hospitalidad restringida sólo aplica si el viajero se encuentra en tránsito, el pasaje de retorno da al Estado la seguridad de dicha transitoriedad.

3) La reserva previa en hotel o albergue también es un criterio de análisis en lo que respecta a la hospitalidad. En efecto, los viajeros son investidos bajo el manto del hospitium sólo si poseen una morada que les de cobijo. Debido a que los diferentes viajeros recurrirán a la oferta hotelera, la reserva de una habitación es condición sinequanón de protección.

4) La bebida alcohólica o no-alcohólica es otro factor que denota una buena predisposición hacia el extranjero. Si las tribus Lodagaa en África brindan cerveza a los extranjeros como signo de hospitalidad, los hoteles modernos hacen lo propio con cocktails de bienvenida, o rituales de otro tipo ya sea a la entrada o a la salida del hotel. Cuando el viajero ingresa, el ritual de bienvenida le da la investidura que lo protegerá durante toda su estadía; en analogía al banquete greco-romano, la comida se presenta como un aspecto fundamental en la configuración de la alteridad. A su partida el viajero debe devolver la hospitalidad comprometiéndose a brindar la misma protección si es visitado en su lugar de origen; surge en este contexto, el rito de despedida y la promesa de un pronto reencuentro.

5) Por último, el dinero en tanto código específico de transacción que habla del patrimonio del migrante o viajero también funcionaría como un indicador de hospitalidad. Como ya se ha discutido, el viajero cuyo patrimonio es 
declarado al Estado anfitrión, es protegido por las leyes de quien otorga la hospitalidad.

6) Otro aspecto importante es el uso de un lenguaje intermediario entre el huésped y el anfitrión, o el uso del lenguaje propio del visitante. En este caso, el turismo y la hospitalidad moderna hacen uso del inglés como esa lengua hibrida que permite al viajero sentirse cómodo y seguro. Como el griego, el latín o el francés, el inglés se ha transformado en una lengua internacional que acompaña a los procesos de hospitalidad. En este sentido, la incomprensión de la lengua es una de las maneras de generar hostilidad en el extranjero.

\section{Conclusión}

Como se ha expuesto, la hospitalidad se habría constituido en la antigüedad clásica como una herramienta de solidaridad político-militar con arreglo a ciertos criterios sacro-religiosos que dependiendo cada circunstancia podía ser comercializada o no; en la actualidad, su funcionamiento continúa despertando más dudas que certezas y no existen trabajos de profundidad que hayan investigado el fenómeno. En parte, esto se debe a que la hospitalidad conserva un lado oscuro por el cual el viajero se pone en inferioridad de condiciones con otros actores locales aumentando el grado de vulnerabilidad. Pero también la hospitalidad puede ser considerada como un permiso de protección temporal de los peligros que aquejan a cualquier viajero. El presente artículo, en este contexto, ha intentado ser un aporte al estudio socio-histórico de la misma comprendiendo que la historia antigua ejerce sobre nuestras conductas la función de un espejo. Recurrir a ella, es entre otras cosas, comprender nuestro propio presente y la forma compleja en que operan los fenómenos sociales en la vida cotidiana.

\section{Referencias}


ALBO, Xavier. La experiencia religiosa Aymará. En: Rostros Indios de Dios, cuadernos de investigación. La Paz: CIPCA, UCB, 1992.

ÁLVAREZ, Estefanía. Aspecto económico de la penetración y colonización romana en Asturias. Revista Emérita, 31, 1963.

BALANDIER, George. Antropología política. Buenos Aires: Ediciones del Sol, 2004.

BAHRDT, Hans. La moderna metrópoli: reflexiones sociológicas sobre la construcción en las ciudades. Buenos Aires: Eudeba, 1970.

BALBIN-CHAMORRO, Paloma. Ius hospitii y ius civitatis. Gerión, 1 (1), 2006, pp.:207-235

BLAZQUEZ, Jose María. Nuevos estudios sobre la romanización. Madrid: Ediciones ITSMO, 1989.

BORDIEU, Pierre. Las estructuras sociales de la Economía. Buenos Aires: Editorial Manantial, 2001.

CESAR, Julio. C. Comentarios sobre la guerra de la Galia. Buenos Aires: Editorial Losada, 2004.

CICERON, Marco. T. La adivinación. Buenos Aires: Ed. Hyspamerica, 1985.

COHEN, Abner. Antropología política: el análisis del simbolismo en las relaciones de poder. En: Llobera J. (comp). Antropología política. Madrid: Anagrama. 1985, Pp. 55-81.

DELGADO-OLIVA, Alfredo. Estado actual de la teoría del apego. Revista de Psiquiatría y Psicología del Niño y del Adolescente, 4 (1), 2004, pp. 55-69.

DERRIDA, Jacques. (2006). La hospitalidad. Buenos Aires: Ediciones de la Flor. D `ORS, Alvaro. (1953). Epigrafía jurídica de la España romana. Madrid

ELIADE, Mircea. (2006). El mito del eterno retorno. Buenos Aires: Emece Editores.

ELIAS, Norbert. La civilización de los padres y otros ensayos. Bogotá: Editorial Norma, 1998.

ETIENNE, Roux. at al. La tessera hospitalis, instrument de sociabilité et de romanisation dans la Peninsule Ibérique. Sociabilite, pouvoirs et societe. Actes du colloque de Rouen 1983, Rouen, 1987, pp. 323-336.

FERNANDEZ-JUAREZ, G. Tutela de las sombras: enfermedad y cultura en el Altiplano Aymará. En: Sustentos, aflicciones y postrimerías de los indios de América. Madrid: Casa de América, 2000.

FRAZER, George. La rama dorada. Bogotá: Fondo de Cultura Económica, 1993. FOUCAULT, Michel. Defender la sociedad. Buenos Aires: Fondo de Cultura Económica, 2000.

GEERTZ, C. Negara. El estado-teatro en Bali del siglo XIX. Buenos Aires: Editorial Paidos, 2000.

GOODY, Jack. Cocina, cousine y clase: estudio de sociología comparada. Barcelona: Gedisa, 1995.

GRIMAL, Pierre. El helenismo y el auge de Roma: el mundo mediterráneo en la edad antigua II. Buenos Aires: Editorial Siglo XXI, 2002.

GYGAX, Marc. D. El intercambio de dones en el mundo griego: reciprocidad, imprecisión, equivalencia y desequilibrio. Gerión, 25 (1), 2007, pp. 111-126. 
HALBWACHS, Maurice. Las clases sociales. México: Fondo de Cultura Económica, 1952.

HOBBES, Thomas. Leviatán. Buenos Aires: Ediciones Libertador, 2004.

HUMBERT, Michel. Municipium et civitas sine sufragio. L'organisation de la conquete jusqu' a la guerre sociale. Roma, 1978.

JIMENEZ-GUZMAN Luis. Fernando. Teoría turística: un enfoque integral del hecho social. Bogotá: Universidad Externado de Colombia, 1986.

LEVI-STRAUSS, Claude. El pensamiento salvaje. México: Fondo de Cultura Económica, 2003.

MALINOWSKI, Bronislaw. Los argonautas del Pacífico Occidental. Barcelona: Editorial Planeta-Agostini, 1986.

MAUSS, Marcel. Ensayo sobre los dones: motivo y formas del cambio en las sociedades primitivas. Madrid: Editorial Técnos, 1979

PAGDEN, Anthony. Señores del todo el mundo: ideologías del imperio en España, Inglaterra, y Francia (en los siglos XVI, XVII y XVIII). Buenos Aires: Editorial Península, 1997.

RAMOS Y LOSCERTALES, J. M. Hospicio y clientela en la España Céltica. Revista Emerita (10), 1948, pp. 308-337

SAHLINS, Marshal. Stone Age Economics. Londres: Routledge, 1972.

SAHLINS, Marshal. Islas de Historia: la muerte del Capitán Cook, metáfora, antropología e historia. Barcelona: Editorial Gedisa, 1988.

SOLA, María D. Mitología romana. Buenos Aires: Editorial Gradifico, 2004.

SENECA, Lucio Anneo. Cartas Morales a Lucillio. Tomos I y II. Buenos Aires: Ediciones Orbis, 1984

WALDENFELS, Bernhard. El habitar físico en el espacio. En: Teoría de la cultura: un mapa de la cuestión. Schroeder, Gerhardt y Greuniger, Elga (Compiladores). Buenos Aires: Fondo de Cultura Económica, 2005, pp. 157:178.

WEINER, Annete. Inalienable possessions: the paradox of keeping-whilegiving. Berkeley: University of California Press, 1992. 